\title{
Atemnot und Brustschmerzen nach NSAR-Gabe
}

\section{Ein 63-jähriger Mann mit Ulkus- anamnese und einer vor kurzem er- folgten Behandlung mit NSAR suchte wegen akut aufgetretener Atemnot und Brustschmerzen die Nothilfe auf. Er war hypoton und tachykard und hatte unter Sauerstoffbeatmung über die Nasensonde eine Sauer- stoffsättigung von $92 \%$.}

- Die Röntgen-Thorax-Aufnahme zeigte Luft im Perikard (Abb. A, Pfeil). Die Computertomografie des Thorax bestätigte die Diagnose eines großen Pneumoperikardiums (Abb. B, Pfeil), allerdings weder einen Pneumothorax noch ein Pneumoperitoneum. Es wurde eine notfallmäßige Perikardiozentese durchgeführt und eine große Menge Luft aspiriert. Unmittelbar darauf normalisierten sich die Vitalparameter des
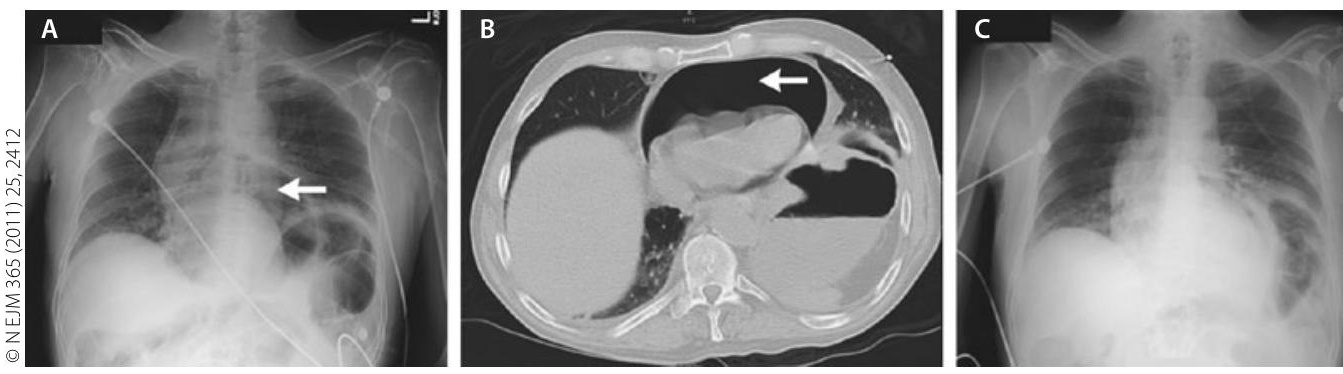

Das Pneumoperikardium im Röntgen-Thorax und CT (A, B). Therapiekontrolle (C).

Patienten. Eine Kontrollaufnahme des Thorax ergab einen wesentlichen Rückgang des Pneumoperikardiums (Abb. C).

Bei weiteren Untersuchungen ergab sich, dass der Patient eine Fistelung vom Magenfundus aus durch das Zwerchfell in den Perikardraum aufwies, die durch ein penetrierendes peptisches Ulkus verursacht war. Die Fistel musste schließlich chirurgisch verschlossen werden.

H. S. FÜESSL =
- A. Adrianov, M.A. Nissenbaum

(Korres.: alexmd2@gmail.com): Pneumopericardium associated with a peptic ulcer. New Engl. J. Med. 365 (2011) 25, 2412.

\section{AchtUNG:}

\section{Hier muss der Dummy durch eine Anzeige ersetzt werden !!}

